\title{
Propagation of desert moss Syntrichia caninervis in peat pellet: a method for rapidly obtaining large numbers of cloned gametophytes
}

\author{
Xiujin Liu \\ Xinjiang Institute of Ecology and Geography https://orcid.org/0000-0003-2096-7705 \\ Ping Zhou \\ Xinjiang Institute of Ecology and Geography \\ Xiaoshuang Li \\ Xinjiang Institute of Ecology and Geography \\ Daoyuan Zhang ( $\nabla$ zhangdy@ms.xjb.ac.cn) \\ University of Chinese Academy of Sciences https://orcid.org/0000-0001-5026-7617
}

Research

Keywords: Leaf, Shoot, Stem, Rihizoid, Gametophyte, Regeneration, Peat pellet

Posted Date: January 13th, 2021

DOI: https://doi.org/10.21203/rs.3.rs-143310/v1

License: (c) (i) This work is licensed under a Creative Commons Attribution 4.0 International License. Read Full License

Version of Record: A version of this preprint was published at Plant Methods on April 21st, 2021. See the published version at https://doi.org/10.1186/s13007-021-00740-7. 


\section{Abstract \\ Background}

Syntrichia caninervis is a typical desiccation tolerance moss, which is a dominant species forming biological soil crust in the Gurbantunggut Desert. This study investigated the effect of different explants on regeneration potential by propagating on peat pellet.

\section{Result}

Juvenile and green leaves can regenerate secondary protonema within one week and shoot in half a month in peat pellet. Rhizoid has strong ability to regenerate, like leaf regeneration, the secondary protonema is the dominant type of regenerant. The process of stem regeneration is similar with whole gametophyte. Stem is the most important integral body part when propagation. The whole gametophyte is the most optimal materials for rapidly propagating.

\section{Conclusion}

This article improves the state of our current knowledge in desiccation tolerance moss cultivation, highlighting efforts to effectively obtain large number of gametophytes through different parts of explant. This work provides a useful resource for the research of $S$. caninervis as well as biocrust restoration.

\section{The Study Design}

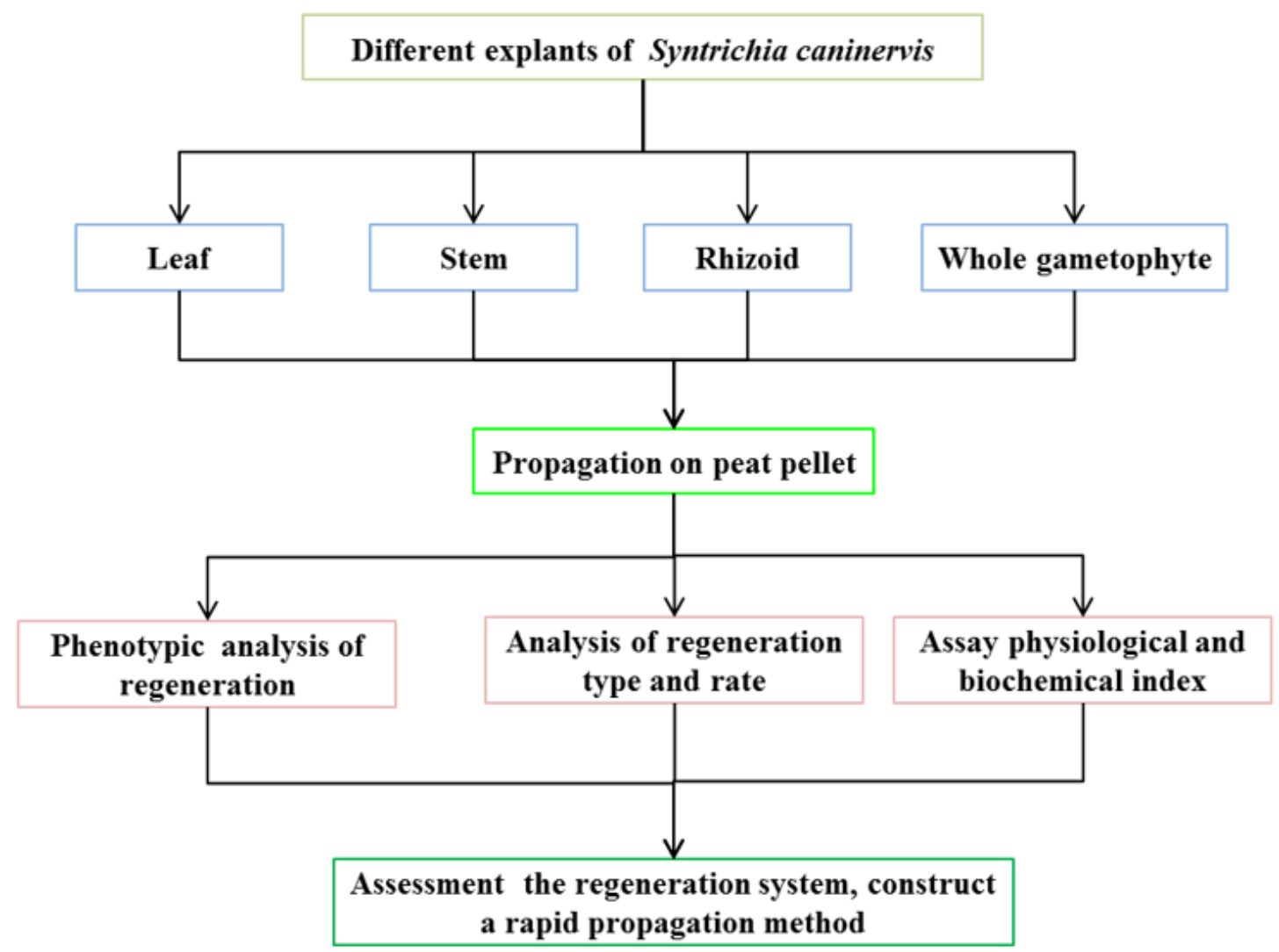

We propagated the vegetative fragments (leaf, stem, rhizoid) and whole gametophyte from Syntrichia caninervis in peat pellet. We observed regeneration phenotypic of different explants, analysed the regeneration type and rate, assayed physiological and biochemical index. Furthermore, we compared our study with others. Finally, we constructed a rapid propagation method.

\section{Introduction}


Bryophytes such as liverworts, hornworts, and mosses that first emerged 480 million years ago and are widespread across the world from moist tropical rainforests to dry desert. Bryophytes have no true roots, stems, leaves, or water transport system compared with seed plants. They have retained the poikilohydry and desiccation tolerance that are probably the optimal pattern of adaptation at their scale [1]. Desiccation tolerance (DT, also desiccation tolerant) is the ability to revive from protoplasmic water losses of up to $80-90 \%$ [2]. Desiccation tolerance mosses are important components of biological soil crusts in some desert ecosystems. Biological soil crusts are a community of interacting organisms, including cyanobacteria, algae, lichens, and bryophytes that live in and bind the top millimeters of mineral soil [3]. These desiccation tolerance mosses play important roles in stabilizing soil surfaces to prevent erosion [4], contributing carbon through photosynthesis, fixing nitrogen, and mediating the hydrological cycle in desert [5].

World-wide distribution bryophytes have constructed a well-developed system for propagating. Physcomitrella patens as model species in bryophytes, it has a series of successful regeneration method at its gametophytes or sporophytes stage [6]. In addition, the culture techniques of $P$. patens protoplast regeneration are also well-known [7]. Sphagnum species is an important economic and ecological model moss, they can regenerate by sporophytes germination or gametophytes cultivation on different media [8]. Atrichum undulatum belongs to desiccation tolerance moss, it can more efficiently propagate by protoplast regeneration [9]. Syntrichia ruralis is widely accepted model species for desiccation tolerance moss [10], it still has regenerate ability after 20 years in the herbarium [11], these mosses firstly observed regeneration after 18 days cultivation on native habit sand, most regenerant shoot or protonema located at the upper of the original shoot. However, it isn't adequate for desiccation tolerance moss regeneration relative to mentioned famous moss.

Syntrichia caninervis Mitt. (Pottiaceae) $[12,13]$ has become a new model plant for studies of desiccation tolerance, dehydration, and rehydration [14-17]. It is a dominant species forming biological soil crusts in the Gurbantunggut Desert [18]. It is also found in Tengger Desert of central Asia arid areas [19,20], and in the Mojave Desert of North America [21]. It's very important in maintaining and restoring in the desert ecosystem [3]. In the past, the research of S. caninervis was focused on distribution [22], physiological and biochemical characteristics [16], the cycle of dehydration and rehydration [17, 23], sex ratio and sexual reproduction [21, 24, 25], desiccation tolerance mechanism [26], and gene exploration [27-29], meanwhile, S. caninervis genome published in 2020 [30].

S. caninervis is dioecious bryophytes, it doesn't commonly undergo sexual reproduction, propagation in nature is assumed to be mostly clonal, and in desert species, a extremely skewed female-biased sex ratio and infrequent sexual reproduction [31], therefore, our research about regeneration based on asexual reproduction. Until now, several studies have confirmed that detached leaves of $S$. caninervis are capable of efficient regeneration $[14,21,32]$. In Stark's study, younger leaves regenerate protonema and shoots more quickly, extend protonem filaments much farther, produce shoots more quickly, and accumulate much more biomass than older leaves, in addition, female leaves regenerate much more shoots than male leaves after 56 days cultivation in native habitat soil. Xu et al. [32] reported that detached leaves can regenerate a large amount of protonema after a month of cultivation in agar-solid Knop medium, and transplanting in situ regenerated protonema to soil supplemented with liquid Knop medium can produce much more shoots after another month. Besides, shoot tip also can regenerate the secondary protonema and shoot. According to the above, $S$. caninervis primarily regenerating through leaf explant in native habitat soil required 2 months. Till now, the regeneration ability of rhizoid has not been studied, therefore, the effect of different explants is incomplete. The study requires much efficient substrate regenerate $S$. caninervis.

In order to optimize different explants with regard to regeneration efficiencies, a short and detailed version of the $S$. caninervis propagation method was researched. We carried out a large-scale artificial propagation method of desiccation tolerance moss, inoculating fragments or entire moss on the peat pellet in a plantlet bottle. The method has simple operation process, short reproductive cycle, big biological quantity, universality. It can realize desiccation tolerance moss resource regenerating, provide foundation for further study. In view of the crucial role of desiccation tolerance moss in restoration desert ecological system, we have applying optimization cultivation to obtain mass-produced S.caninervis.

\section{Results}

\section{Leaf regeneration}

Leaf explants taken from juvenile and green leaves were used to propagation. Regenerant protonema firstly observed at $4.31 \pm 1.56 \mathrm{~d}$ cultivation (Table 1), protonema initially occured on leaf basal, after a few days, germinated from apical of leaf (Fig. 1). About 4 - $7 \mathrm{~d}$ of culture, the protonema germination rate was $100 \%$, and all of leaves regeneration were firstly producing secondary protonema. A new secondary leaves emerged after $12.31 \pm 2.03 \mathrm{~d}$ of cultivation, while they were in a minority (Fig. 7, Table 1 ). Leaves can produce shoots both from the secondary protonema and directly from leaf tissue. Protonema is the dominant type of leaf explant propagating.

\section{Rhizoid regeneration}


After $12 \mathrm{~d}$ of culture, it was the first time that observing secondary protonema germinated from rhizoid explant, and protonema initially germinated from medial (Fig. 2). The regenerant shoots emerged after 1 month cultivation (33.08 $\pm 7.08 \mathrm{~d}$, Table 1). Only a few rhizoids germinated the secondary shoot, and these regenerant shoots were produced by the secondary protonema. We found that protonema was the dominant regeneration type when rhizoid as explants, only rare rhizoid can produce the secondary shoot after $56 \mathrm{~d}$ cultivation (Table 1).

\section{Stem regeneration}

Fragments from stem explants firstly emerged secondary shoot after $5.76 \pm 1.28 \mathrm{~d}$ of cultivation (Fig. 3). After $4 \mathrm{~d}-7 \mathrm{~d}$ cultivation, the gametophyte germination rate was $100 \%$. The secondary protonema emerged after $10.69 \pm 1.73 \mathrm{~d}$ cultivation, while they were not dominant regenerant type (Table 1). It's different from leaf explant propagating, the secondary shoot is the dominant type of stem explant regenerating. The process of stem regeneration was similar with whole gametophyte, while they took much more time when germination of shoot and protonema (Table 1).

\section{The whole gametophyte regeneration}

The process of whole gametophytes regeneration can be seen in Fig. 4 and Additional file 2, we found that stem was dominant part of regeneration, and secondary shoot is the major type when entire gametophyte reproducing. The secondary protonema emerged two days later than shoot, the regenerant shoot firstly germinated at $2 \mathrm{~d}$ cultivation, and the regenerant protonema firstly geminated at $4 \mathrm{~d}$ cultivation (Fig. 5a, Table 1). Before 23 days, the regeneration rate of protonema and gametophytes continuously increase, and protonema was still lower than gametophyte (Fig. 5a). Based on shoot growth rate, it suggested that $12 \mathrm{~d}$ cultivation had the largest germination number in gametophyte and protonema (Fig. 5b), therefore, $12 \mathrm{~d}$ had the highest vitality. After $32 \mathrm{~d}$ cultivation, regenerated shoot had covered the original gametophyte (Fig. 4), and the regeneration rate kept invariable (Fig. 5a). After $56 \mathrm{~d}$ cultivation, both original gametophytes and secondary shoot became old (Fig. 4). Therefore, we have chosen $32 \mathrm{~d}$ regenerant materials to examine water content, chlorophyll content and the ability of photosynthesis (Fig. 6). We found that water content and chlorophyll content have no significant difference between field and regenerant (Fig. $6 \mathrm{a}, \mathrm{b}$ ), while the ratio of $\mathrm{Chl} \mathrm{a/b}$ from regenerant shoot was significantly higher than the origin gametophyte from field (Fig. 6b). In addition, the regenerant had higher photochemical efficiency than field (Fig. 6c), because the Fv/Fm and Y(II) of regenerant were significantly higher than field.

We overview the propagation profiles, including regeneration type, emergency days and protonema extension, of $S$. caninervis on peat pellets (Fig. 7). In addition, to compare our result with previous work, we summarized the culture substrate, viability, day to shoot or protonema emergency and biomass accumulation from different explants under different subsrate and cultural conditions (Table 1).

\section{Table 1. Different vegetative fragments effect on regenerate potential in S. caninervis}




\begin{tabular}{|c|c|c|c|c|c|c|c|c|c|}
\hline Reference & Explants & Type & $\begin{array}{l}\text { Cultivation } \\
\text { time }\end{array}$ & Substrate & $\begin{array}{l}\text { Viability } \\
(\%)\end{array}$ & $\begin{array}{l}\text { Location of } \\
\text { regeneration }\end{array}$ & $\begin{array}{l}\text { Days to } \\
\text { protonema } \\
\text { emergence }\end{array}$ & $\begin{array}{l}\text { Days to } \\
\text { shoot } \\
\text { emergence }\end{array}$ & $\begin{array}{l}\text { Shoot } \\
\text { number }\end{array}$ \\
\hline \multirow[t]{5}{*}{$\begin{array}{l}\text { Xu et al. } \\
\text { [32] }\end{array}$} & Shoot tip & & 1 month & $\begin{array}{l}\text { Soil } \\
\text { (native } \\
\text { habitat) }\end{array}$ & 100 & $\begin{array}{l}\text { Apical and } \\
\text { basal }\end{array}$ & $5 \pm 0.6$ & - & $2.6 \pm 1.0$ \\
\hline & Leaf & Juvenile & 1 month & $\begin{array}{l}\text { Soil } \\
\text { (native } \\
\text { habitat) }\end{array}$ & 100 & $\begin{array}{l}\text { Medial and } \\
\text { basal }\end{array}$ & $6 \pm 0.8$ & - & $0.7 \pm 0.4$ \\
\hline & & Green & 1 month & $\begin{array}{l}\text { Soil } \\
\text { (native } \\
\text { habitat) }\end{array}$ & 97 & $\begin{array}{l}\text { Apical and } \\
\text { basal }\end{array}$ & $9 \pm 1.5$ & - & $0.2 \pm 0.1$ \\
\hline & & $\begin{array}{l}\text { Yellow- } \\
\text { green }\end{array}$ & 1 month & $\begin{array}{l}\text { Soil } \\
\text { (native } \\
\text { habitat) }\end{array}$ & 93 & Medial & $11 \pm 1.2$ & - & 0 \\
\hline & & Brown & 1 month & $\begin{array}{l}\text { Soil } \\
\text { (native } \\
\text { habitat) }\end{array}$ & 37 & Apical & $23 \pm 5.6$ & - & 0 \\
\hline \multirow[t]{4}{*}{$\begin{array}{l}\text { Stark et } \\
\text { al. [21] }\end{array}$} & Leaf & Juvenile & 56days & $\begin{array}{l}\text { Soil } \\
\text { (native } \\
\text { habitat) }\end{array}$ & 100 & $\begin{array}{l}\text { Medial and } \\
\text { basal }\end{array}$ & 7 & 21 & $2.63 \pm 0.34$ \\
\hline & & Green & 56days & $\begin{array}{l}\text { Soil } \\
\text { (native } \\
\text { habitat) }\end{array}$ & 98 & Basal & 9 & - & $3.12 \pm 0.5$ \\
\hline & & $\begin{array}{l}\text { Yellow- } \\
\text { green }\end{array}$ & 56days & $\begin{array}{l}\text { Soil } \\
\text { (native } \\
\text { habitat) }\end{array}$ & 98 & Apical & 22 & - & - \\
\hline & & Brown & 56days & $\begin{array}{l}\text { Soil } \\
\text { (native } \\
\text { habitat) }\end{array}$ & 88 & Medial & 31 & - & - \\
\hline \multirow[t]{2}{*}{$\begin{array}{l}\text { Stark et } \\
\text { al. [14] }\end{array}$} & Leaf & Female & 56days & $\begin{array}{l}\text { Soil } \\
\text { (native } \\
\text { habitat) }\end{array}$ & 100 & - & 11 & 34 to 47 & 3.4 \\
\hline & & Male & 56days & $\begin{array}{l}\text { Soil } \\
\text { (native } \\
\text { habitat) }\end{array}$ & 100 & - & 17 & 34 to 47 & 6 \\
\hline $\begin{array}{l}\text { This } \\
\text { study }\end{array}$ & Leaf & Green & 56days & $\begin{array}{l}\text { Peat } \\
\text { pellet }\end{array}$ & 100 & $\begin{array}{l}\text { Medial and } \\
\text { basal }\end{array}$ & $4.31 \pm 1.56$ & $12.31 \pm 2.03$ & $2.95 \pm 0.82$ \\
\hline & Rhizoid & & 56days & $\begin{array}{l}\text { Peat } \\
\text { pellet }\end{array}$ & 100 & Medial & $12 \pm 1.12$ & $33.08 \pm 7.08$ & $0.6 \pm 0.44$ \\
\hline & Stem & & 32days & $\begin{array}{l}\text { Peat } \\
\text { pellet }\end{array}$ & 100 & Whole stem & $10.69 \pm 1.73$ & $5.76 \pm 1.28$ & $5.43 \pm 1.65$ \\
\hline & Gametophyte & & 56days & $\begin{array}{l}\text { Peat } \\
\text { pellet }\end{array}$ & 100 & Stem & $7.93 \pm 2.93$ & $4.39 \pm 1.56$ & $8.79 \pm 3.72$ \\
\hline
\end{tabular}

\section{Discussion}

Moss propagating has been studied both on different media (soil, solid or liquid tissure culture medium) and on different types (tissue regeneration, de novo organogenesis, and somatic embryogenesis) [33].Tissue regeneration is the ability of plant repairing from wounding 
sites such as leaf, stem or root tip. De novo organogenesis is regenerating new organs either from detached organs or from the original plant. Excised gametophyte leaf from $P$. patens can regenerate to entire plant. Somatic embryogenesis is a single somatic cell dedifferentiates into an embryo cell, and the new embryo cell develop to form a whole plant [34]. Protoplast regeneration is similar with somatic embryogenesis, a single protoplast from moss can regenerate into a whole plant. $S$. caninervis regeneration is similar with De novo organogenesis. In the paper, we established an effective regeneration system through entire gametophyte or fragments (leaf, stem, rhizoid) on peat pellet.

The effect of different explants on moss regeneration potential was assessed by taking in situ soil as substrate and nutrient source, young age leaves (juvenile and green leaves) regenerate more quickly, extend protonemal filament farther, produce more shoots, accumulate much more biomass than older leaves (yellow-green and brown leaves, Table 1) [21]. Female detached leaves regenerated protonema more quickly than male leaves, and eventually produced more shoots (Table 1) [14]. The time spending in regeneration prononema in $S$. caninervis, in turn, is shoot tip, juvenile leaf, green leaf, yellow-green leaf, brown leaf [32]. We have verified the regeneration ability of leaf, rhizoid, stem explant and whole gametophyte.

Detached leaves as explant can regenerate. In Pleurochaete squarrosa, excision leaf regenerate buds and filaments (looks like caulonemata and chloronemata) [35]. Physcomitrella patens regeneration is the de novo regeneration of chloronema apical cells from excised gametophyte leaf cells [36]. In S. caninervis, protonema is the dominant regeneration type in detached leaves. Detached leaves firstly produce protonema in $4.31 \pm 1.56 \mathrm{~d}$ cultivation (Table 1 ), it is significantly much rapider than regenerate rates observed and cultured in soil [21]. A significant number of secondary leaves emerged after two months of cultivation in soil [32], while shoot emergence from leaves in $12.31 \pm 2.03 \mathrm{~d}$ cultivation when peat pellet as substrate. Therefore, peat pellet is a good substrate for propagation.

Seed plants can produce heavily branching extensive root systems supporting their growth on dry land conditions [37]. In the Arabidopsis root explant, the secondary shoots emerged from the xylem-pole pericycle cells which containing pluripotent stem cells for shoot regeneration [38]. However, bryophytes don't have root, they have rhizoid which are similar morphology and function. Rhizoids initiate from an epidermal cell of a gametophore stem, like an anchor fixating the leafy gametophores on their growth substrate, and acquire nutrition [39]. There are several reports about rhizoid development $[39,40]$, while the knowledge of rhizoid regeneration is insufficient in bryophytes, we found that rhizoids of $S$. caninervis produce protonema in $12 \pm 1.12 \mathrm{~d}$ cultivation, and it took more than 1 month for secondary shoot regeneration. Although, rhizoid and leaf was protonema dominant rereneration, rhizoid took an extra week more than leaf explants when regenerating (Table 1).

We cutted apical and rhizoid of gametophyte as stem explant, it can regenerate. In higher plant regeneration, cuttage is typical stem regeneration, the bottom wounds of stem give rise to secondary roots, top or sidewounds forms shoots. In $S$. caninervis, the secondary shoot is dominant regeneration type of stem explant. Stem explant obviously took less time to regenerate the secondary shoot than leaf or rhizoid explant (Table 1). Unlike higher plant, the secondary shoots emerge from cutting site, the locations of shoot regeneration ranged from the apex to the base of stem explants in S. caninervis (Fig. 3). When the whole gametophytes as explant for regenerating, its regeneration rate reached $100 \%$ after $15 \mathrm{~d}$ cultivation (Fig. 5a). According to shoot growth rate, gametophytes got the best vitality at $12 \mathrm{~d}$ cultivation (Fig. $5 \mathrm{~b}$ ). After $32 \mathrm{~d}$ of culture, every original moss regenerated about 8.5 new shoots (Table 1). After $56 \mathrm{~d}$ of culture, regenerated shoot became old (Fig. 4). We also found that the secondary shoot is dominant regeneration type when entire gametophyte as regenerant material.

Histological studies using different explants from $S$. caninervis showed that all of them give rise to regenerant protonema and shoots. Morphological characters of regenerant protonema or shoot had no obviously varied among leaf, rhizoid and stem explants. The regenerant material was distinctly different types of body parts, shoot was dominant forms which regenerant from entire gametophytes or stem explants. It should be pointed out that the fast regeneration for $S$. caninervis asexual reproduction was whole gametophyte as regenerant material (Fig. 7), stem explant has similar regeneration process with whole gametophyte. A large number of protonema were induced to grow by breeding detached green leaves or rhizoid in peat pellet after half month as day/night temperature were set at $25 / 15{ }^{\circ} \mathrm{C}$. We firstly found that rhizoid is the best explant for regenerating protonema in S. caninervis. Based on the life cycle of $S$. caninervis in cultivation, a procedure for artificial propagation of desiccation tolerance moss was established and assessed. A desiccation tolerance moss dominated crusts may form through propagation $S$. caninervis in peat pellet. P. patens as model plant in bryophyte was a unique system for studying the molecular basis of stem cell reprogramming due to the ability of differentiated cells to re-enter the cell cycle, and can regenerate into whole plants[41]. According to our result, $S$. caninervis as model plant in desiccation tolerance moss, its leaf, rhizoid, stem possess stem cell totipotency, because they have the ability of regenerating the whole plant, and the regenerant comparing with the original from field have much higher photochemical efficiency (Fig. 6c). It is useful in stem cell reprogramming, desiccation mechanism revealing, and biocrust restoration in the future. 
For now, the substrate of $S$. caninervis regeneration was soil (dominant by fine sand) collecting from native habitat [14, 32], while desert soils are spatially heterogeneous, nutrient limited systems. Based on our result, the peat pellet is much more suitable than desert soil for regeneration, like a "fertile islands". The micro-habitat was constant in a number of parameters, including temperature,moisture, light intensity, and nutrients. The growth substrate contains nutrient and fiber components such as peat and coco which are compression molded into pellet. It increased nutrient availability (including organic matter, total and available nitrogen, phosphorus, potassium) and provide more favorable environment for $S$. caninervis regeneration and growth. Furthermore, the viability, emergency rate and shoot number are much higher than planted on soil (Table 1). In view of the crucial role of desert mosses in the hydrology of arid areas, we optimized a rapid, effective and easy handled propagation method of $S$. caninervis, which can help reconstruction of moss dominated soil crusts and restore desert ecosystem in the future.

\section{Conclusion}

In this report, an efficient regeneration of S. caninervis, an model dessication tolerance moss, was established via the whole or different fragments of gamephytes (leaf, stem, rhizoid). The whole gametophyte or stem explant are ideal for quickly mass propagation of clonal material, while leaf and rhizoid explants are best candidate for protonema regeneration, especially rhizoid. The peat pellet is a perfect substrate for propagating moss.

\section{Materials And Methods}

\section{Plant material and preparation}

Dry Syntrichia caninervis gametophytes were collected from the Gurbantunggut Desert in Xinjiang-Uyghur Autonomous Region, China $\left(44^{\circ} 32 \varangle 30 \varangle \mathrm{N}, 88^{\circ} 6 \varangle 42 \varangle \mathrm{E}\right)$ and kept in the dark in a paper sack at room temperature. Dry gametophytes were fully re-hydrated on filter paper saturated with distilled water $(9 \mathrm{~mL})$ in glass petri dishes for $24 \mathrm{~h}$ at $25^{\circ} \mathrm{C}$, with light at a photosynthetic photon flux density (PPFD) of 50 $\mu \mathrm{mol} / \mathrm{m}^{2} / \mathrm{s}$. To remove surface impurities and sand, the fully hydrated $S$. caninervis was transferred to a glass beaker, stirred lightly using a glass rod for $3 \mathrm{~min}$, fished out using sieve, then put into another beaker. The washing was repeated five times. The washed gametophytes were placed on filter paper in Petri dishes, prior to regeneration.

\section{Cultivation of vegetative fragments}

The vegetative fragments (leaf, stem, rhizoid) and entire gametophyte of $S$. caninervis were separately sown on peat pellet (JiffyCorp., Manitoba, Canada). For reducing contamination, we placed a peat pellet in tissue culture vessels (350 mL, height $108 \mathrm{~mm}$, diameter $75 \mathrm{~mm}$, caliber $69 \mathrm{~mm}$, lid with air hole), then dry autoclaved for $30 \mathrm{~min}$ at $121^{\circ} \mathrm{C} .100 \mathrm{~mL}$ distilled water was applied to sterile peat pellet, after a few minutes, peat pellet swelled by drinking water, prior to cultivation (Additional file 1). The whole gametophyte regeneration was conducted as follow: we picked 80 fully hydrated gametophytes (as mentioned in Plant material and preparation), and separated 20 repeats, every repeat included 4 individuals. The leaf regeneration was conducted as follow: we randomly selected and sampled 10 gametophytes, the juvenile and green leaves were chosen for propagation and cultivated in peat pellet, isolated juvenile and green leaves using the method of Stark et al. [21]. Each leaf placed on the substrate, adaxial surface up, in the growth chamber. The stem regeneration was conducted as follow: we cut stem apices (with juvenile and green leaves) and rhizoid, just kept middle part, and put them on peat pellet. The rhizoid was detached and sown on peat pellets. Growth chambers were set with a $16 \mathrm{~h} / 8 \mathrm{~h}$ photoperiod, light intensity was about $150 \mu \mathrm{mol} / \mathrm{m}^{2} / \mathrm{s}$, and day/night temperatures of $25^{\circ} \mathrm{C} / 15^{\circ} \mathrm{C}$. Relative humidity in the chamber was approximately $60 \%$ for the duration of the experiment.

\section{Morphological observation}

The whole plant, stem, leaf and rhizoid were sown and grew on peat pellet, we observed them in situ. Regeneration process were observed through a stereomicroscope (SZX-16, OlympusCorp., Tokyo, Japan), and photographs were taken using a digital camera (DP74, OlympusCorp., Tokyo, Japan). Adobe Photoshop software (ver. 6.01, Adobe Systems Inc., San Jose, USA) was used to edit the digital images. The regeneration of whole gametophytes noted on $0 \mathrm{~d}, 3 \mathrm{~d}, 6 \mathrm{~d}, 9 \mathrm{~d}, 12 \mathrm{~d}, 15 \mathrm{~d}, 19 \mathrm{~d}, 23 \mathrm{~d}, 32 \mathrm{~d}, 56 \mathrm{~d}$. The regeneration of stems observed at $0 \mathrm{~d}, 4 \mathrm{~d}, 6 \mathrm{~d}, 9 \mathrm{~d}, 12 \mathrm{~d}, 16 \mathrm{~d}, 32 \mathrm{~d}, 56 \mathrm{~d}$. The regeneration of protonema and shoot from leaf were noted on $0 \mathrm{~d}, 4 \mathrm{~d}, 6 \mathrm{~d}, 9 \mathrm{~d}, 12 \mathrm{~d}$, $16 \mathrm{~d}, 32 \mathrm{~d}, 56 \mathrm{~d}$. The regeneration of rhizoid observed at $0 \mathrm{~d}, 12 \mathrm{~d}, 16 \mathrm{~d}, 32 \mathrm{~d}, 56 \mathrm{~d}$.

\section{Protonema extension}

After $56 \mathrm{~d}$ cultivation, the extension of protonema filaments from different explants measured by ImageJ (the National Institute of Health, Wisconsin, USA). The linear distance from the edge of original explants (leaf, rhizoid, stem, entire gametophyte) to the furthest extent of protonema extension was determined. 
Room temperature was $25^{\circ} \mathrm{C}$, relative humidity was $30 \% .32 \mathrm{~d}$ S. caninervis were placed on filter paper, and redundant water on plant surfaces was absorbed using another piece of filter paper. We weighted 200 milligram (mg) as Wt, and then were placed in the Petri dish, and weighed (Dwt) after drying in an oven for $15 \mathrm{~min}$ at $105^{\circ} \mathrm{C}$, and at $65^{\circ} \mathrm{C}$ for $48 \mathrm{~h}$. The water content (g H $\mathrm{O}_{2} \mathrm{O} / \mathrm{g} \mathrm{Dwt}$ ) was calculated as (Wt - Dwt)/Dwt. The ratio was measured three biological replicates and six technical replicates and then averaged.

\section{Gametophyte regeneration assay}

Every plantlet bottle containing one peat pellet, and 4 individuals were sown on each pellet. Shoot or protonema occurrence, days to shoot or protonema emergence, and shoot number were recorded for entire regeneration stage (days 56). Regeneration rate (\%) was determined as the number of gametophytes produced protonema or shoot divided by the total number of sown gametophytes. Shoot growth rate (\%) was determined as the number of shoots divided by the number of days from emergence to the end of the experiment (days 56).

\section{Pigment analysis}

Chlorophyll content was measured according to the methods described by Ritchie 2006[42]. We collected 40 mg fresh weight $S$. caninervis from $32 \mathrm{~d}$ old complete plant. Pigments were extracted by incubation of the entire plant in $2 \mathrm{~mL}$ of $96 \%$ ethanol (room temperature about $25^{\circ} \mathrm{C}$ ) for $4 \mathrm{~h}$ in darkness with constant agitation. The extracts were centrifuged at 10000 rpm for 2 min and the supernatants removed for analysis. Supernatants were analyzed spectrophotometrically at wavelengths of $470 \mathrm{~nm}, 649 \mathrm{~nm}$, and $665 \mathrm{~nm}$ using a UV-visible spectrophotometer (Biomate 3S, Thermo Fisher Scientific, Waltham, USA). The concentration of the chlorophyll a, b and total carotenoids were determined using the following equations: $\mathrm{Chl} a=13.95 * \mathrm{OD}_{665}-6.88 * \mathrm{OD}_{649}, \mathrm{Chl} \mathrm{b}=24.96 * \mathrm{OD}_{649}{ }^{-7.32}{ }^{*} \mathrm{OD}_{665}, \mathrm{and}_{\mathrm{Car}}=\left(1000^{*} \mathrm{OD} \mathrm{D}_{470}\right.$

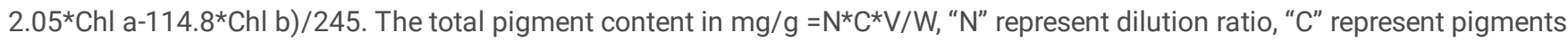
concentration $(\mathrm{mg} / \mathrm{mL})$, " $\mathrm{V}$ " represent the volume of extracting solution $(\mathrm{mL})$, " $\mathrm{W}$ ” represent sample fresh weight (g).

\section{Fluorometric assessment photosynthetic performance}

Photosynthetic performance of regenerated $S$. caninervis assessed by pulse amplitude modulated flassessed using a portable chlorophyll fluorometer (PAM 2500) (Heinz, Walz, Germany). Measurements of chlorophyll fluorescence were recorded in situ. The saturation pulse method was used to calculate the Fv/Fm. Fo and Fm were measured in the dark after dark adaption for greater than 30 min. The parameter settings were based on the recommendations of Zhang et al. [43]. The Y(II) of samples were measured at ambient light, saturating pulses were applied to determine the maximal fluorescence yield during actinic illumination, Fm' and the steady-state level luorescence during actinic illumination $\mathrm{F}$. The values of $\mathrm{Y}(\mathrm{II})$ were calculated by $\mathrm{Y}(\mathrm{II})=(\mathrm{Fm}-\mathrm{F}) / \mathrm{Fm}^{\prime}$. All parameters were measured three biological replicates and three technical replicates and then averaged.

\section{Statistical analysis}

All statistical analyses were performed using Statistical Product and Service Solutions (SPSS) 16.0 software (SPSS Inc., Chicago, USA). Data were compared using one-way ANOVA, a post hoc LSD test was used to examine difference in the significance of ANOVA results, and values were considered statistically significantly different at $P<0.05$, or distinctly statistically different at $P<0.01$. Error bars represent standard deviations.

\section{Declarations}

\section{Ethics approval and consent to participate}

Not applicable.

\section{Consent for publication}

Not applicable.

\section{Availability of data and materials}

The datasets used and/or analyzed during the current study are available from the corresponding authors on reasonable request.

\section{Competing interests}

The authors declare that they have no competing interests. 


\section{Funding}

This work was supported by NSFC (National Natural Science Foundation of China) -Xinjiang key project (No.U1703233), Key Research Program of Frontier Sciences, CAS (ZDBS-LY-SM009), and the Youth Innovation Promotion Association, Chinese Academy of Sciences (No.2018478).

\section{Author contribution}

XJL and DYZ conceived and designed research. XJL conducted experiments. XSL and PZ contributed analytical tools. XJL analyzed data and wrote the manuscript. All authors read and approved the manuscript.

\section{Acknowledgement}

We are thankful to Dr. Tohir Bozorov for valuable suggestions to the manuscript.

\section{Author information}

${ }^{1}$ State Key Laboratory of Desert and Oasis Ecology, Xinjiang Instistute of Ecology and Geography, Chinese Academy of Sciences, Urumqi 830011 , China. ${ }^{2}$ University of Chinese Academy of Sciences, Beijing 100049. ${ }^{3}$ Turpan Eremophytes Botanical Garden, Chinese Academy of Sciences, Turpan, 838008.

\section{References}

1. Proctor MCF, Oliver MJ, Wood AJ, Alpert P, Stark LR, Cleavitt NL, Mishler BD. Desiccation-tolerance in bryophytes: a review. Bryologist. 2007, 110:595-621.

2. Oliver MJ, Tuba Z, Mishler BD. The evolution of vegetative desiccation tolerance in land plants. Plant Ecol. 2000, 151(1):85-100.

3. Antoninka A, Faist A, Rodriguez-Caballero E, Young KE, Chaudhary VB, Condon LA, Pyke DA. Biological soil crusts in ecological restoration: emerging research and perspectives. Restoration Ecology. 2020, 28:S3-S8.

4. Cole C, Stark LR, Bonine ML, McLetchie DN. Transplant Survivorship of Bryophyte Soil Crusts in the Mojave Desert. Restoration Ecology. 2010, 18(2):198-205.

5. Ferrenberg S, Tucker CL, Reed SC. Biological soil crusts: diminutive communities of potential global importance. Frontiers in Ecology and the Environment. 2017, 15(3):160-167.

6. Cove DJ, Perroud P-F, Charron AJ, McDaniel SF, Khandelwal A, Quatrano RS. Culturing the moss Physcomitrella patens. Cold Spring Harbor protocols. 2009, 2009(2):pdb.prot5136.

7. Schween G, Hohe A, Koprivova A, Reski R. Effects of nutrients, cell density and culture techniques on protoplast regeneration and early protonema development in a moss, Physcomitrella patens. Journal of plant physiology. 2003, 160(2):209-212.

8. Heck MA, Lueth VM, van Gessel N, Krebs M, Kohl M, Prager A, Joosten H, Decker EL, Reski R. Axenic in vitro cultivation of 19 peat moss (Sphagnum L.) species as a resource for basic biology, biotechnology, and paludiculture. New Phytologist. 2021, 229(2):861-876.

9. Li LH, Wang XP, Hou WR, Liu XL, He YK. An efficient protocol for plant regeneration from protoplasts of the moss Atrichum undulatum PBeauv in vitro. Plant Cell Tiss Org. 2005, 82(3):281-288.

10. Oliver MJ, Velten J, Wood AJ. Bryophytes as experimental models for the study of environmental stress tolerance: Tortula ruralis and desiccation-tolerance in mosses. Plant Ecol. 2000, 151(1):73-84.

11. Stark LR, Greenwood JL, Brinda JC. Desiccated Syntrichia ruralis shoots regenerate after 20 years in the herbarium. Journal of Bryology. 2017, 39(1):85-93.

12. Kramer W. Contribution to taxonomy and distribution of several taxa of Tortula Hedw. sect. rurales denot (Musci) with bistratose lamina. Bryologist. 1978, 81(3):378-385.

13. Gallego MT, Cano MJ, Ros RM, Guerra J. New taxonomic data on a circum-tethyan group of Syntrichia (pottiaceae, bryophyta): the $S$. caninervis complex. Systematic Botany. 2002, 27(4):643-653.

14. Stark LR, Nichols L, McLetchie DN, Bonine ML. Do the sexes of the desert moss Syntrichia caninervis differ in desiccation tolerance? A leaf regeneration assay. International Journal of Plant Sciences. 2005, 166(1):21-29.

15. Xu SJ, Chen WH, Chen YW, Wang CF, Wang Y. Electron paramagnetic resonance study of amphiphiles partitioning behavior in desiccation-tolerant moss during dehydration. Chinese Chemical Letters. 2007, 18(7):865-868. 
16. Li Y, Wang ZB, Xu TH, Tu WF, Liu C, Zhang YM, Yang CH. Reorganization of photosystem II is involved in the rapid photosynthetic recovery of desert moss Syntrichia caninervis upon rehydration. Journal of plant physiology. 2010, 167:1390-1397.

17. Gao B, Zhang D, Li X, Yang H, Wood AJ. De novo assembly and characterization of the transcriptome in the desiccation-tolerant moss Syntrichia caninervis. BMC research notes. 2014, 7:490.

18. Zhang YM, Wang HL, Wang XQ, Yang WK, Zhang DY. The microstructure of microbiotic crust and its influence on wind erosion for a sandy soil surface in the Gurbantunggut Desert of Northwestern China. Geoderma. 2006, 132(3-4):441-449.

19. Liu LC, Li SZ, Duan ZH, Wang T, Zhang ZS, Li XR. Effects of microbiotic crusts on dew deposition in the restored vegetation area at Shapotou, northwest China. Journal of Hydrology. 2006, 328(1-2):331-337.

20. Li XR, Wang XP, Li T, Zhang JG. Microbiotic soil crust and its effect on vegetation and habitat on artificially stabilized desert dunes in Tengger Desert, North China. Biology and Fertility of Soils. 2002, 35(3):147-154.

21. Stark LR, Nichols L, McLetchie DN, Smith SD, Zundel C. Age and sex-specific rates of leaf regeneration in the Mojave Desert moss Syntrichia caninervis. American journal of botany. 2004, 91(1):1-9.

22. Zhang YM, Chen J, Wang L, Wang XQ, Gu ZH. The spatial distribution patterns of biological soil crusts in the Gurbantunggut Desert, Northern Xinjiang, China. Journal of Arid Environments. 2007, 68(4):599-610.

23. Wu N, Zhang YM, Downing A, Aanderud ZT, Tao Y, Williams S. Rapid adjustment of leaf angle explains how the desert moss, Syntrichia caninervis, copes with multiple resource limitations during rehydration. Funct Plant Biol. 2014, 41(2):168-177.

24. Stark LR, McLetchie DN, Eppley SM. Sex ratios and the shy male hypothesis in the moss Bryum argenteum (Bryaceae). Bryologist. 2010, 113(4):788-797.

25. Benassi M, Stark LR, Brinda JC, McLetchie DN, Bonine M, Mishler BD. Plant size, sex expression and sexual reproduction along an elevation gradient in a desert moss. Bryologist. 2011, 114(2):277-288.

26. Coe KK, Greenwood JL, Slate ML, Clark TA, Brinda JC, Fisher KM, Mishler BD, Bowker MA, Oliver MJ, Ebrahimi S, et al. Strategies of desiccation tolerance vary across life phases in the moss Syntrichia caninervis. American journal of botany. 2020.

27. Wang JC, Yang HL, Gao B, Bozorov TA, Li XS, Zhang DY, Wood AJ. Analysis and characterization of the Aldehyde dehydrogenase $(A L D H)$ gene superfamily in the desert moss Syntrichia caninervis in response to abiotic stress. Environmental and Experimental Botany. 2020, 178.

28. Liu XJ, Zhang YG, Yang HL, Liang YQ, Li XS, Oliver MJ, Zhang DY. Functional Aspects of Early Light-Induced Protein (ELIP) Genes from the Desiccation-Tolerant Moss Syntrichia caninervis. Int J Mol Sci. 2020, 21(4).

29. Li XS, Liang YQ, Gao B, Mijiti M, Bozorov TA, Yang HL, Zhang DY, Wood AJ. ScDREB10, an A-5c type of DREB Gene of the Desert Moss Syntrichia caninervis, Confers Osmotic and Salt Tolerances to Arabidopsis. Genes. 2019, 10(2).

30. Silva AT, Gao B, Fisher KM, Mishler BD, Ekwealor JTB, Stark LR, Li X, Zhang D, Bowker MA, Brinda JC, et al. To dry perchance to live: Insights from the genome of the desiccation-tolerant biocrust moss Syntrichia caninervis. The Plant journal: for cell and molecular biology. 2020.

31. Bowker MA, Stark LR, McLetchie DN, Mishler BD. Sex expression, skewed sex ratios, and microhabitat distribution in the dioecious desert moss Syntrichia caninervis (Pottiaceae). American journal of botany. 2000, 87(7):924-924.

32. Xu SJ, Yin CS, He M, Wang Y. A Technology for Rapid Reconstruction of Moss-Dominated Soil Crusts. Environmental Engineering Science. 2008, 25(8):1129-1137.

33. Xu L, Huang H. Genetic and Epigenetic Controls of Plant Regeneration. In: Mechanism of Regeneration. 2014,108:1-33.

34. Yang XY, Zhang XL. Regulation of Somatic Embryogenesis in Higher Plants. Critical Reviews in Plant Sciences. 2010, 29(1):36-57.

35. Giordano S, Alfano F, Esposito A, Spagnuolo V, Basile A, Cobianchi RC. Regeneration from detached leaves of Pleurochaete squarrosa (Brid) Lindb in culture and in the wild. Journal of Bryology. 1996, 19:219-227.

36. Ishikawa M, Murata T, Sato Y, Nishiyama T, Hiwatashi Y, Imai A, Kimura M, Sugimoto N, Akita A, Oguri Y, et al. Physcomitrella CyclinDependent Kinase A Links Cell Cycle Reactivation to Other Cellular Changes during Reprogramming of Leaf Cells. Plant Cell. 2011, 23(8):2924-2938.

37. Motte H, Vanneste S, Beeckman T. Molecular and Environmental Regulation of Root Development. In: Annual Review of Plant Biology. 2019,70: 465-488.

38. Atta R, Laurens L, Boucheron-Dubuisson E, Guivarc'h A, Carnero E, Giraudat-Pautot V, Rech P, Chriqui D. Pluripotency of Arabidopsis xylem pericycle underlies shoot regeneration from root and hypocotyl explants grown in vitro. Plant Journal. 2009, 57(4):626-644.

39. Menand B, Yi KK, Jouannic S, Hoffmann L, Ryan E, Linstead P, Schaefer DG, Dolan L. An ancient mechanism controls the development of cells with a rooting function in land plants. Science. 2007, 316(5830):1477-1480. 
40. Sakakibara K, Nishiyama T, Sumikawa N, Kofuji R, Murata T, Hasebe M. Involvement of auxin and a homeodomain-leucine zipper I gene in rhizoid development of the moss Physcomitrella patens. Development. 2003, 130(20):4835-4846.

41. Kofuji R, Hasebe M. Eight types of stem cells in the life cycle of the moss Physcomitrella patens. Current opinion in plant biology. 2014, 17:13-21.

42. Ritchie RJ. Consistent sets of spectrophotometric chlorophyll equations for acetone, methanol and ethanol solvents. Photosynthesis research. 2006, 89(1):27-41.

43. Zhang J, Zhang YM, Downing A, Wu N, Zhang BC. Photosynthetic and cytological recovery on remoistening Syntrichia caninervis Mitt., a desiccation-tolerant moss from Northwestern China. Photosynthetica. 2011, 49(1):13-20.

\section{Reference Website}

1

https://doi.org/10.1639/0007-2745(2007)110[595:DIBAR]2.0.C0;2

2

https://link.springer.com/article/10.1023/A:1026550808557

3

https://onlinelibrary.wiley.com/doi/full/10.1111/j.1526-100X.2008.00445.x

4

https://onlinelibrary.wiley.com/doi/full/10.1111/rec.13201

5

https://esajournals.onlinelibrary.wiley.com/doi/abs/10.1002/fee.1469

6

http://cshprotocols.cshlp.org/content/2009/2/pdb.prot5136

7

https://www.sciencedirect.com/science/article/pii/S017616170470396X?via\%3Dihub

8

https://nph.onlinelibrary.wiley.com/doi/10.1111/nph.16922

9

https://link.springer.com/article/10.1007/s11240-005-1370-z

10

https://link.springer.com/article/10.1023\%2FA\%3A1026598724487

11

https://www.tandfonline.com/doi/full/10.1080/03736687.2016.1176307

12

https://www.jstor.org/stable/3242240 
http://www.jstor.org/stable/3093912

14

https://www.journals.uchicago.edu/doi/10.1086/425671

15

https://www.sciencedirect.com/science/article/pii/S1001841707002239?via\%3Dihub 16

https://www.sciencedirect.com/science/article/pii/S0176161710003536?via\%3DiDih 17

https://bmcresnotes.biomedcentral.com/articles/10.1186/1756-0500-7-490

18

https://www.sciencedirect.com/science/article/pii/S0016706105001990?via\%3Dihub 19

https://www.sciencedirect.com/science/article/pii/S0022169406000060?via\%3Di

hub

20

https://link.springer.com/article/10.1007\%2Fs00374-002-0453-9

21

http://www.jstor.org/stable/4121727

22

https://www.sciencedirect.com/science/article/pii/S0140196306002345?via\%3Dihub 23

https://www.publish.csiro.au/fp/FP13054

24

https://bioone.org/journals/the-bryologist/volume-113/issue-4/0007-2745-113.4.7

88/Sex-ratios-and-the-shy-male-hypothesis-in-the-moss/10.1639/0007-2745-113.4.788.short

25

https://bioone.org/journals/the-bryologist/volume-114/issue-2/0007-2745-114.2.277/P

lant-size-sex-expression-and-sexual-reproduction-along-an-elevation/10.1639/0007-2745-114.2.277.short

26

https://bsapubs.onlinelibrary.wiley.com/doi/10.1002/ajb2.1571

27

https://www.sciencedirect.com/science/article/pii/S0098847220302021?via\%3Dihub

Page $12 / 17$ 
https://www.mdpi.com/1422-0067/21/4/1411

29

https://www.mdpi.com/2073-4425/10/2/146

30

https://onlinelibrary.wiley.com/doi/10.1111/tpj.15116

31

https://bsapubs.onlinelibrary.wiley.com/doi/full/10.2307/2656990

32

https://www.liebertpub.com/doi/10.1089/ees.2006.0272

33

https://www.sciencedirect.com/science/article/pii/B9780123914989000097?via\%3Dihub

34

https://www.tandfonline.com/doi/abs/10.1080/07352680903436291?journalCode=bpts20

35

https://www.tandfonline.com/doi/abs/10.1179/jbr.1996.19.2.219

36

http://www.plantcell.org/content/23/8/2924

37

https://www.annualreviews.org/doi/10.1146/annurev-arplant-050718-100423

38

https://onlinelibrary.wiley.com/doi/full/10.1111/j.1365-313X.2008.03715.x

39

https://science.sciencemag.org/content/316/5830/1477

40

https://dev.biologists.org/content/130/20/4835

41

https://www.sciencedirect.com/science/article/pii/S1369526613001568?via\%3Dihub

42

https://link.springer.com/article/10.1007\%2Fs11120-006-9065-9

43

http://ps.ueb.cas.cz/artkey/phs-201101-0002_photosynthetic-and-cytological-recovery-on-remoistening-syntrichia-caninervis-mitt-adesiccation-tolerant-mos.php

Page 13/17 


\section{Figures}

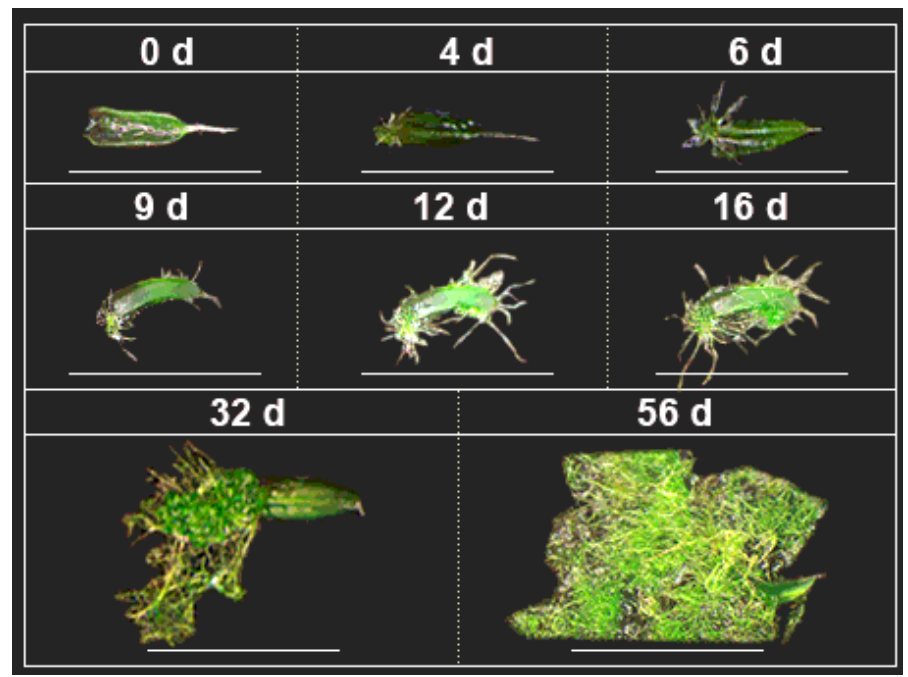

Figure 1

Regeneration of leaf explant in Syntrichia caninervis $(\mathrm{bar}=2 \mathrm{~mm}$ ). Peat pellet was directly used as the substrate and nutrient source. Leaf explants cultured $56 \mathrm{~d}$ (days), photograph were taken in situ peat pellet at $0 \mathrm{~d}, 4 \mathrm{~d}, 6 \mathrm{~d}, 9 \mathrm{~d}, 12 \mathrm{~d}, 16 \mathrm{~d}, 32 \mathrm{~d}, 56 \mathrm{~d}$ cultivation.

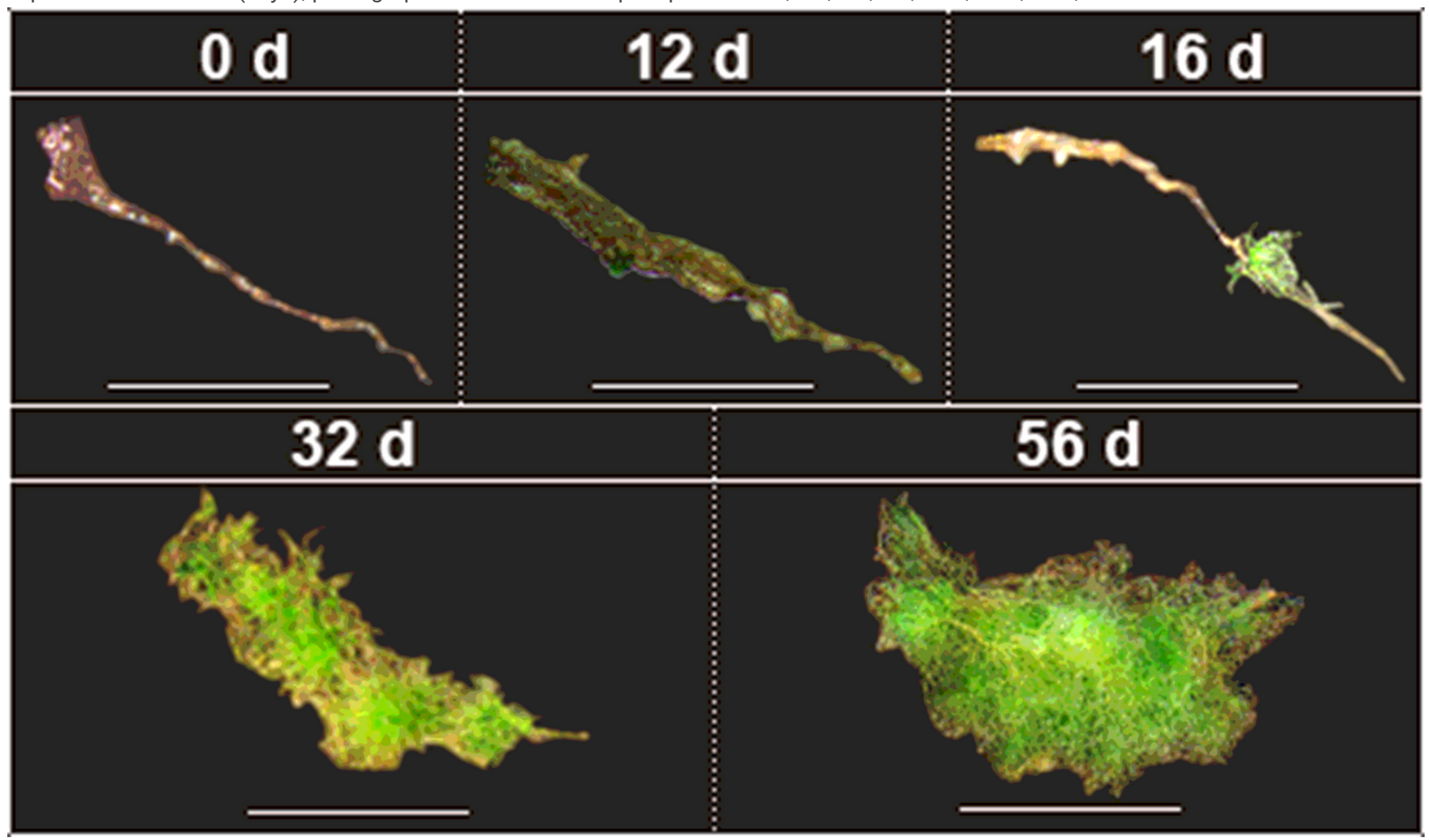

\section{Figure 2}

Regeneration of rhizoid explant in Syntrichia caninervis $(\mathrm{bar}=2 \mathrm{~mm})$. Peat pellet was directly used as the substrate and nutrient source. Rhizoid explants cultured $56 \mathrm{~d}$ (days), photograph were taken in situ peat pellet at $0 \mathrm{~d}, 12 \mathrm{~d}, 16 \mathrm{~d}, 32 \mathrm{~d}, 56 \mathrm{~d}$ cultivation. 


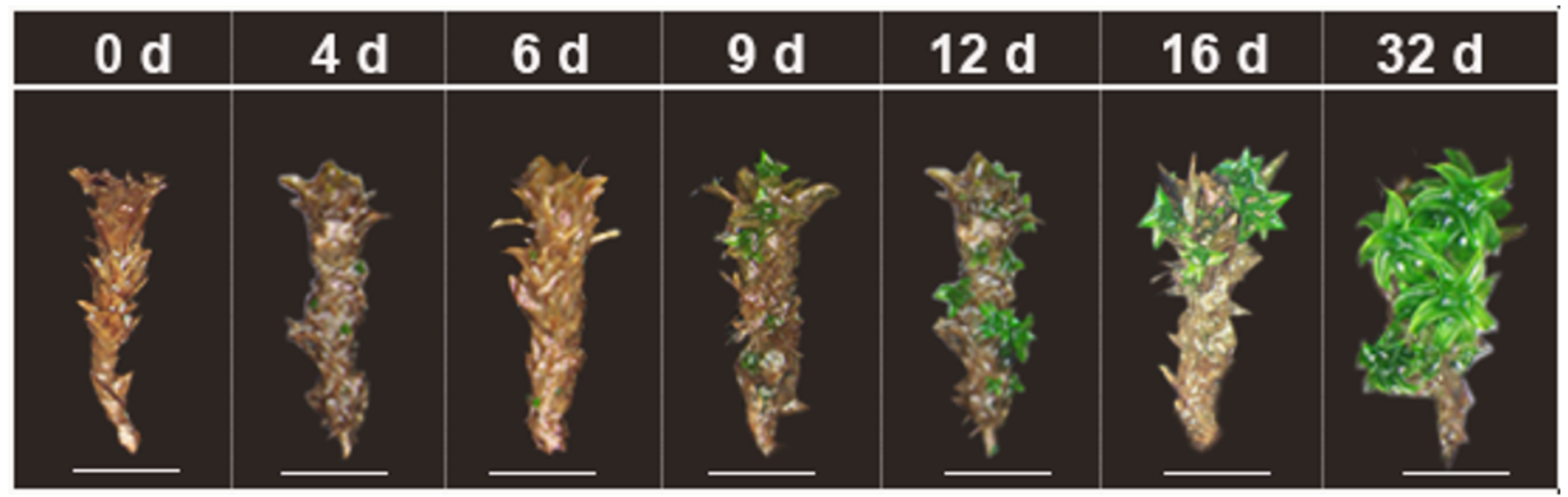

Figure 3

Regeneration of stem explant in Syntrichia caninervis (bar $=2 \mathrm{~mm}$ ). Peat pellet was directly used as the substrate and nutrient source. Leaf explants cultured $32 \mathrm{~d}$ (days), photograph were taken in situ peat pellet at $0 \mathrm{~d}, 4 \mathrm{~d}, 6 \mathrm{~d}, 9 \mathrm{~d}, 12 \mathrm{~d}, 16 \mathrm{~d}, 32 \mathrm{~d}$ cultivation.

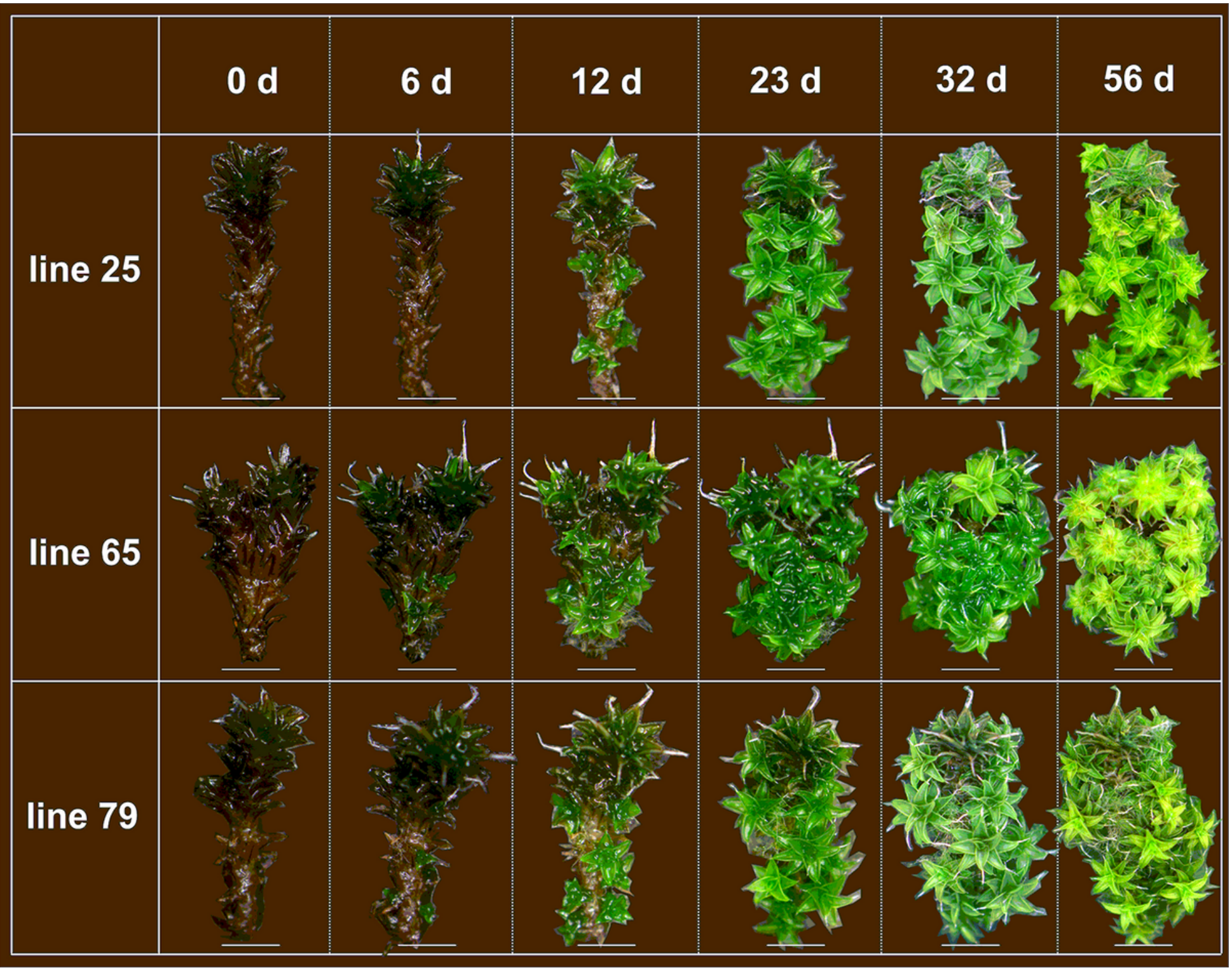

Figure 4 
Regeneration of whole gametophytes in Syntrichia caninervis $(\mathrm{bar}=2 \mathrm{~mm})$. Peat pellet was directly used as the substrate and nutrient source. Whole gametophytes cultured $56 \mathrm{~d}$ (days), photograph were taken in situ peat pellet at $0 \mathrm{~d}, 6 \mathrm{~d}, 12 \mathrm{~d}, 23 \mathrm{~d}, 32 \mathrm{~d}, 56 \mathrm{~d}$ cultivation.
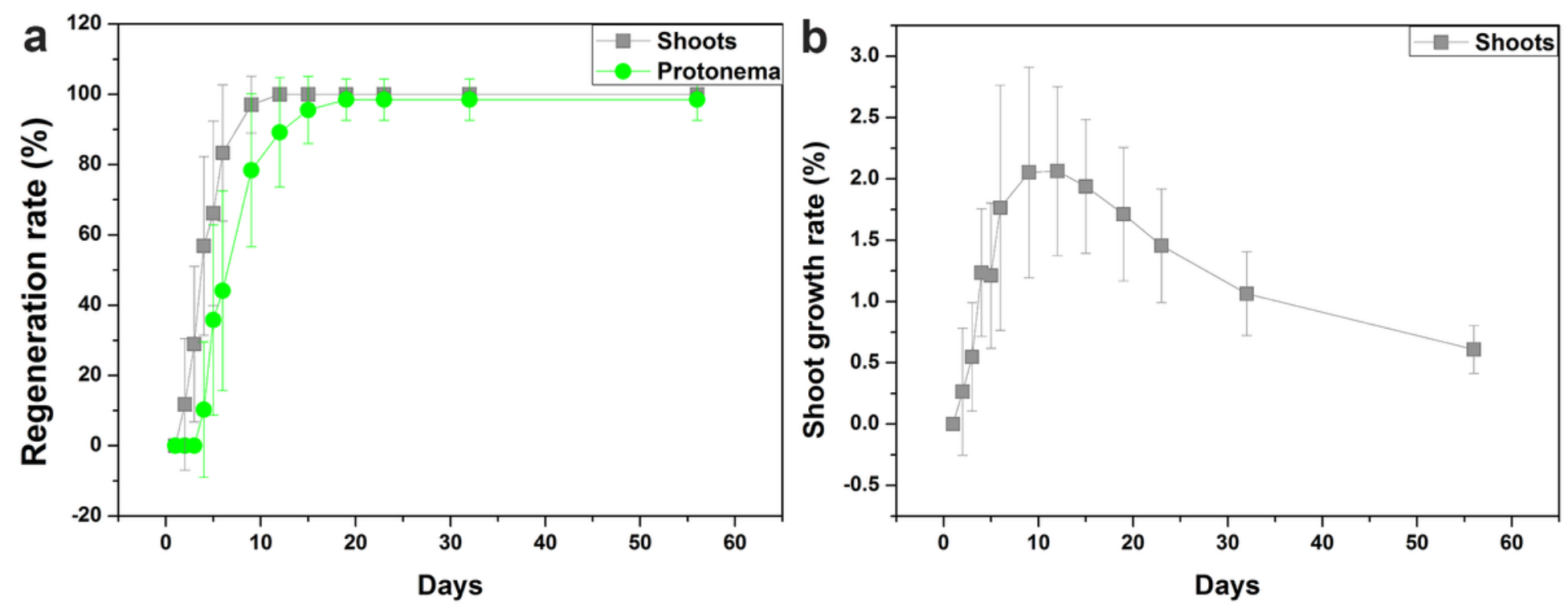

Figure 5

The regenerative variation of the entire gametophyte explant in Syntrichia caninervis. a Regeneration rate (\%). b Shoot growth rate (\%). The whole gametophyte regenerated on peat pellet, after $56 \mathrm{~d}$ in culture (means \pm SD).
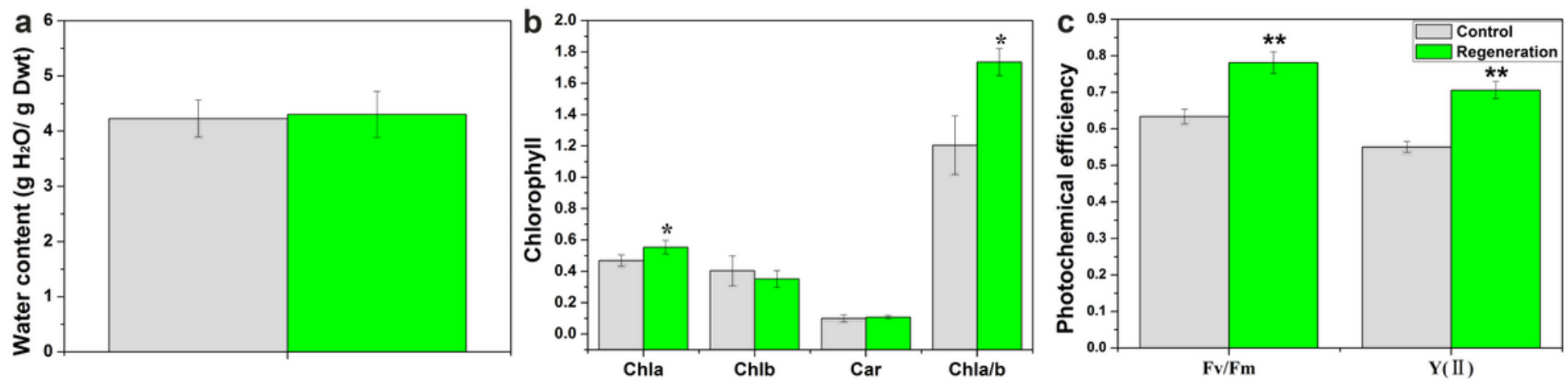

Figure 6

The water content, chlorophyll content and photochemical efficiency of regenerated gametophytes from whole plant in Syntrichia caninervis. a The water content. b The different kind of chlorophyll content. c The maximal photochemical efficiency of PSII (Fv/Fm) and the actual PSII efficiency Y(II). Control was whole gametophyte collected from field and rehydrating $24 \mathrm{~h}$. Regeneration was whole gametophyte regenerated for $32 \mathrm{~d}$ on peat pellet. The mean (each column) and SD (error bar) were calculated with three biological replicates and three technical replicates of each biological replicates. 


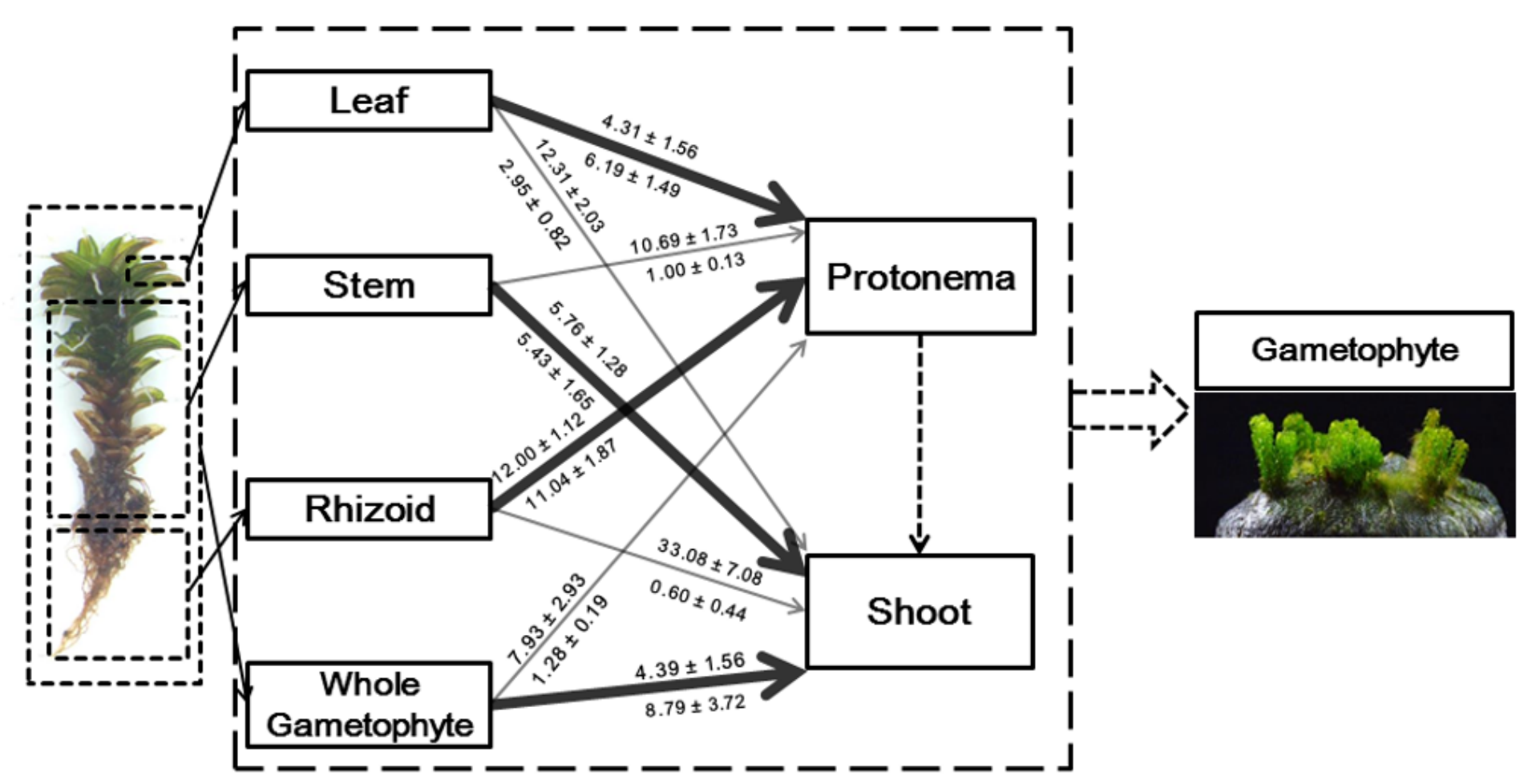

Figure 7

Overview of propagation of S. caninervis in peat pellets. The bold arrow represents dominant regeneration type, fine arrow represents minor regeneration type. The days to shoot or protonema emergence is given on top of the arrow (mean \pm SD). The furthest extent distance of protonema is given beneath the corresponding arrow (mean \pm SD). The number of secondary shoot is given beneath the corresponding arrow (mean $\pm S D$ ).

\section{Supplementary Files}

This is a list of supplementary files associated with this preprint. Click to download.

- Additionalfile1.tif

- Additionalfile2.jpg

- supplementary.docx 